Article

\title{
Biopolymer Solution Evaluation Methodology: Thermal and Mechanical Assessment for Enhanced Oil Recovery with High Salinity Brines
}

\author{
Mohammad A. Al-Saleh *, Abdirahman A. Yussuf, Mohammad A. Jumaa, Abbas Hammoud and \\ Tahani Al-Shammari \\ Petroleum Research Center, Kuwait Institute for Scientific Research, P.O. Box 24885, Safat 13109, Kuwait; \\ ayussuf@kisr.edu.kw (A.A.Y.); mjuma@kisr.edu.kw (M.A.J.); ahamoud@kisr.edu.kw (A.H.); \\ tshamary@kisr.edu.kw (T.A.-S.) \\ * Correspondence: maalsaleh@kisr.edu.kw; Tel.: +965-24956902
}

Received: 22 April 2019; Accepted: 23 May 2019; Published: 5 June 2019

\begin{abstract}
The methodology to study an eco-friendly and non-toxic, Schizophyllan, biopolymer for enhanced oil recovery (EOR) polymer flooding is described. The methodology is divided into two parts; the first part estimates the molar concentration of the biopolymer, which is needed to prepare the biopolymer solution with optimal viscosity. This is required to improve the sweep efficiency for the selected reservoir in Kuwait. The second part of this generalized methodology evaluates the biopolymer solution capability to resist degradation and maintain its essential properties with the selected reservoir conditions. The evaluation process includes thermal and mechanical assessment. Furthermore, to study the biopolymer solution behavior in both selected reservoir and extreme conditions, the biopolymer solution samples were prepared using $180 \mathrm{~g} / \mathrm{L}$ and $309 \mathrm{~g} / \mathrm{L}$ brine. It was found that the prepared biopolymer solution demonstrated great capability in maintaining its properties; and therefore, can be introduced as a strong candidate for EOR polymer flooding with high salinity brines.
\end{abstract}

Keywords: biopolymer; polymer flooding; rheology; thermal stability; mechanical degradation

\section{Introduction}

Enhanced oil recovery (EOR) methods are usually introduced after exhausting the primary and secondary recovery methods to maintain oil production at maximum levels. Currently, there are different EOR methods available for use. However, in the last decade, polymer flooding became one of the most important EOR methods. It gained momentum and renewed interest, in both academic and industrial research due to technological development, and a huge market demand to increase oil production. It improves the water-oil mobility ratio by increasing the viscosity of the injected water in the reservoir, which as a result increases the sweep efficiency and oil recovery [1].

The oil recovery processes are mainly defined as primary, secondary, and tertiary. In the primary process, the oil is produced by the force of the natural energy until depletion is reached. Therefore, a secondary or tertiary process has to be used as an alternative process to enhance the oil recovery. In the secondary process, oil production is assisted by injecting water or natural gas into the reservoir to move the oil to the surface. Tertiary recovery is when oil production is assisted by other means such as injecting steam, micellar solutions, carbon dioxide, and polymer solutions [1,2]. It is expected that the tertiary recovery methods will recover a quantity of oil equivalent to the cumulative oil production to date [3].

Furthermore, the secondary process of water flooding is challenged by a common problem; this problem is identified by the early water breakthrough which can occur in deep formation due to 
heterogeneity or fractures of a reservoir, also because of undesired mobility ratio difference between the displacing and displaced phases, leading to viscous fingering, even in a homogeneous reservoir [3,4]. Therefore, to overcome the undesired mobility ratio differences, tertiary recovery methods were developed as an alternative process. Polymer solutions are used to increase the viscosity of the injected water and increase the percentage of oil displaced from a deep formation. It also lowers the interfacial tension between the oil and water and as a result provides mobility enhancement [5-7]. Therefore, mobility improvement is evaluated by lowering the mobility ratio value, compared to their water floods value. The mobility ratio is defined as $M=\lambda_{\text {ing }} / \lambda_{\text {ed }}$, where $\lambda_{\text {ing }}$ is the mobility ratio of the displacing fluid and $\lambda_{e d}$ is the mobility ratio of the displaced fluid. A value of $M>1$ is considered unfavorable, as it indicates that the displacing fluid flows more readily than the displaced fluid and can cause channeling of the displacing fluid $[1,2,6]$. Thus, the polymer solution viscosity is an important variable in developing suitable polymer solutions for enhanced oil recovery. Several studies on rheological behavior and flow properties in aqueous solutions were reported in the literature [8-11]. In situ-rheology using direct numerical simulation has also been studied [12].

Polymer flooding was reported in the literature and has currently been undergoing successful research steps for a long time with encouraging results produced by several studies for San Francisco and Huntington Beach in the USA, Taber South, in Canada, and Bohai Bay and Daqing, in China [13-18]. The major potential types of water-soluble polymers that are under research to be used as mobility control agents in polymer flooding are polyacrylamides, which are synthetic high molecular weight copolymers, and polysaccharides biopolymers $[19,20]$. However, to the best of our knowledge, limited research has been done using environmentally friendly polymers with high salinity brines. Therefore, the focus of this research was on the preparation and evaluation biopolymer, Schizophyllan, which is a non-ionic and water-soluble homoglucan. This type of biopolymer is made by using strains of wood-rotting and filamentously growing basidiomycete Schizophyllum commune [21]. The chemical structure and subunit of Schizophyllan is shown in Scheme 1.

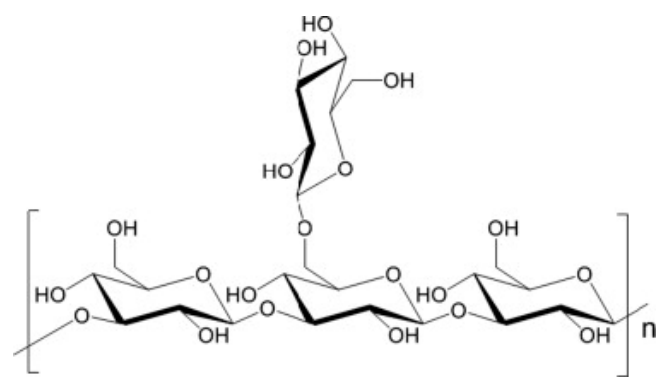

Scheme 1. Structure of Schizophyllan monomer.

Currently, the development of polymer solutions for polymer flooding is facing few challenges, due to viscosity loss caused by the mechanical and chemical degradation at high temperatures. Another major challenge is the high salinity content of the available brine in Kuwait.

In this research, a methodology on the preparation and characterization of environmentally friendly biopolymer solutions is developed and verified with Kuwait reservoir conditions. This general methodology could be applied for future EOR polymer flooding for targeted oil reservoirs. Hence, the biopolymer solution analysis that includes thermal stability and mechanical degradation under reservoir conditions is reported. Further, additional benefit could be found in assisting the oil producer to reduce the amount of water injection needed to enhance oil recovery compared to a conventional water flooding process. 


\section{Experimental}

\subsection{Materials}

Schizophyllan was supplied by the Petroleum Institute of Abu Dhabi to prepare the screening samples with different concentrations and the targeted biopolymer sample with optimal properties. The fresh brine used in the experiments of this research was obtained from sample water injection used in the Sabriya-Maudud (SAMA) reservoir in Kuwait. An additional sample was prepared using synthetic brine, which was formulated to reflect under extreme salinity.

\subsection{Methodology}

The research started with the reservoir selection step, which was conducted to select a candidate reservoir based on its major and potential impact in the future for EOR, using polymer flooding. The reservoir rock formation, temperatures of the injection regions, and salinity of the water sources were included. After the reservoir selection step, the biopolymer solution screening experiment was conducted, in which four biopolymer solutions were prepared within the expected experimental region boundaries that would include the optimal biopolymer solution viscosity, with respect to the selected reservoir. The information from this step was used to minimize the number of trials to prepare and characterize the samples with the targeted viscosity. Therefore, the data of the screening experiments were fitted to a model to estimate the molar concentration that would produce the targeted biopolymer solution viscosity. The characterization sequence was applied throughout the process and special attention was given to the rheological properties, thermal stability, and mechanical degradation for the biopolymer solutions. The overall estimation and evaluation methodology is illustrated in Scheme 2.

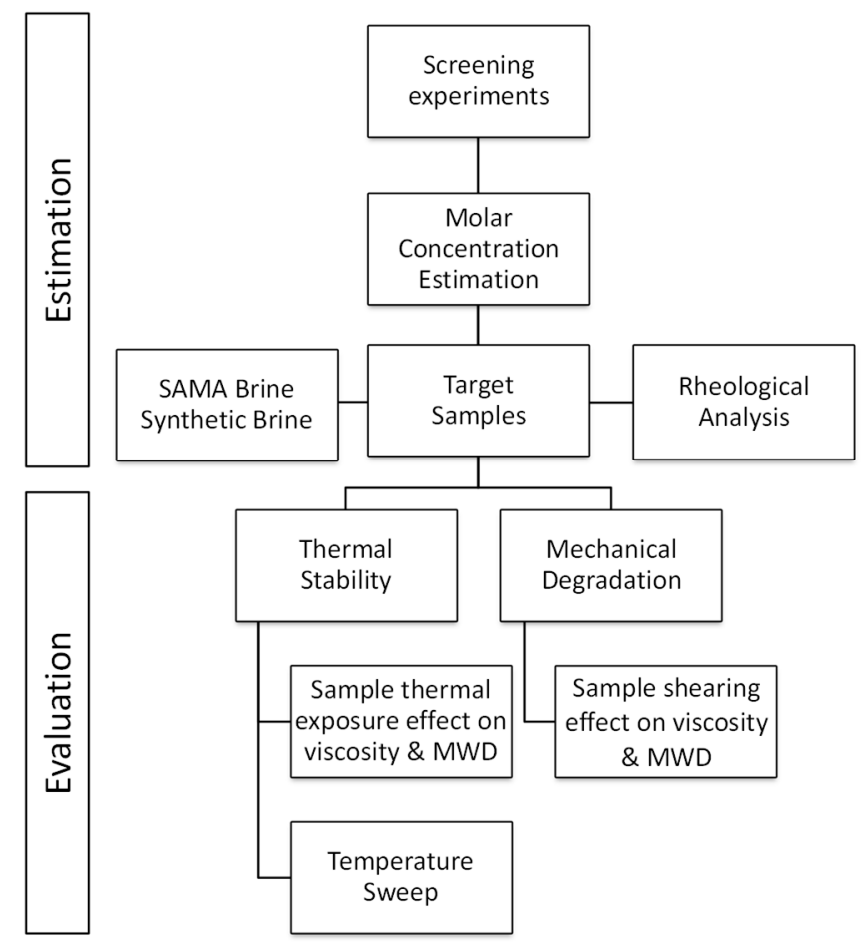

Scheme 2. General estimation and evaluation methodology.

\subsection{Reservoir Selection}

The information for the general reservoir selection was based on a previous study at the Petroleum Research Center of Kuwait Institute for Scientific Research, which included the reservoir rock formation, temperatures of the injection regions, and the salinity of the water sources [22]. Therefore, the Sabriya-Maudud (SAMA) reservoir was selected after refining data and the selection 
was based on the reservoir conditions and further future needs for the local oil industry. The required biopolymer solution for SAMA should be developed with a viscosity of $35 \mathrm{cP}$ at $22{ }^{\circ} \mathrm{C}$ and $7.0 \mathrm{~s}^{-1}$ to meet the needs for the enhanced oil recovery method, knowing that the utilized brine salinity is 180,000 ppm.

\subsection{Brine Preparation}

Fresh brine, used for water injection at SAMA, was used in developing the biopolymer solutions of the screening experiments with a total dissolved solids (TDS) value of 180,000 ppm. The synthetic brine was made to reflect extreme salinity with a TDS value of 309,000 ppm. The extreme salinity brine sample was prepared to explore the salinity effect on the biopolymer solution viscosity and to study the impact of extreme salinity on the biopolymer performance. Table 1 shows the content of two brine sets.

Table 1. Brines total dissolved solids content.

\begin{tabular}{ccc}
\hline Salt & Fresh Brine $(\mathrm{g} / \mathrm{L})$ & Synthetic Brine $(\mathrm{g} / \mathrm{L})$ \\
\hline $\mathrm{NaCl}$ & 134.2 & 240.3 \\
$\mathrm{CaCl}_{2}$ & 31.8 & 52.2 \\
$\mathrm{MgCl}_{2}$ & 9.9 & 12.9 \\
$\mathrm{KCl}$ & 4.3 & 3.7 \\
$\mathrm{TDS}$ & 180.2 & 309.1 \\
\hline
\end{tabular}

\subsection{Screening Region Boundaries of Samples}

Biopolymer solution samples were prepared with four molar concentrations to get the maximum information that allows the optimization routine to estimate the required biopolymer solution molar concentration that would produce the targeted viscosity. These samples were defined by the upper and lower experimental boundaries as shown in Table 2.

Table 2. Biopolymer solutions weight content.

\begin{tabular}{ccccc}
\hline Biopolymer, ppm & $\mathbf{5 0 0}$ & $\mathbf{4 0 0}$ & $\mathbf{3 0 0}$ & $\mathbf{2 0 0}$ \\
\hline Biopolymer, wt & 17.85 & 14.28 & 10.71 & 7.14 \\
Brine, wt & 182.15 & 185.72 & 189.29 & 192.86 \\
\hline
\end{tabular}

The prepared biopolymer solution samples were analyzed for their rheological properties using the Discovery Hybrid Rheometer (HR-3) at $22^{\circ} \mathrm{C}$. The polymer HR-3 peltier plate and peltier concentric cylinder were used in this research work. This step was important to minimize the experimental time to fine-tune the biopolymer viscosity to the targeted value for enhancing oil recovery of the selected reservoir.

The effect of varying the molar concentration on the biopolymer solution viscosity at a given shear rate for the screening experiments is presented in Figure 1. The biopolymer solution with the optimal viscosity for the selected reservoir can be determined from the data provided in Figure 1. 


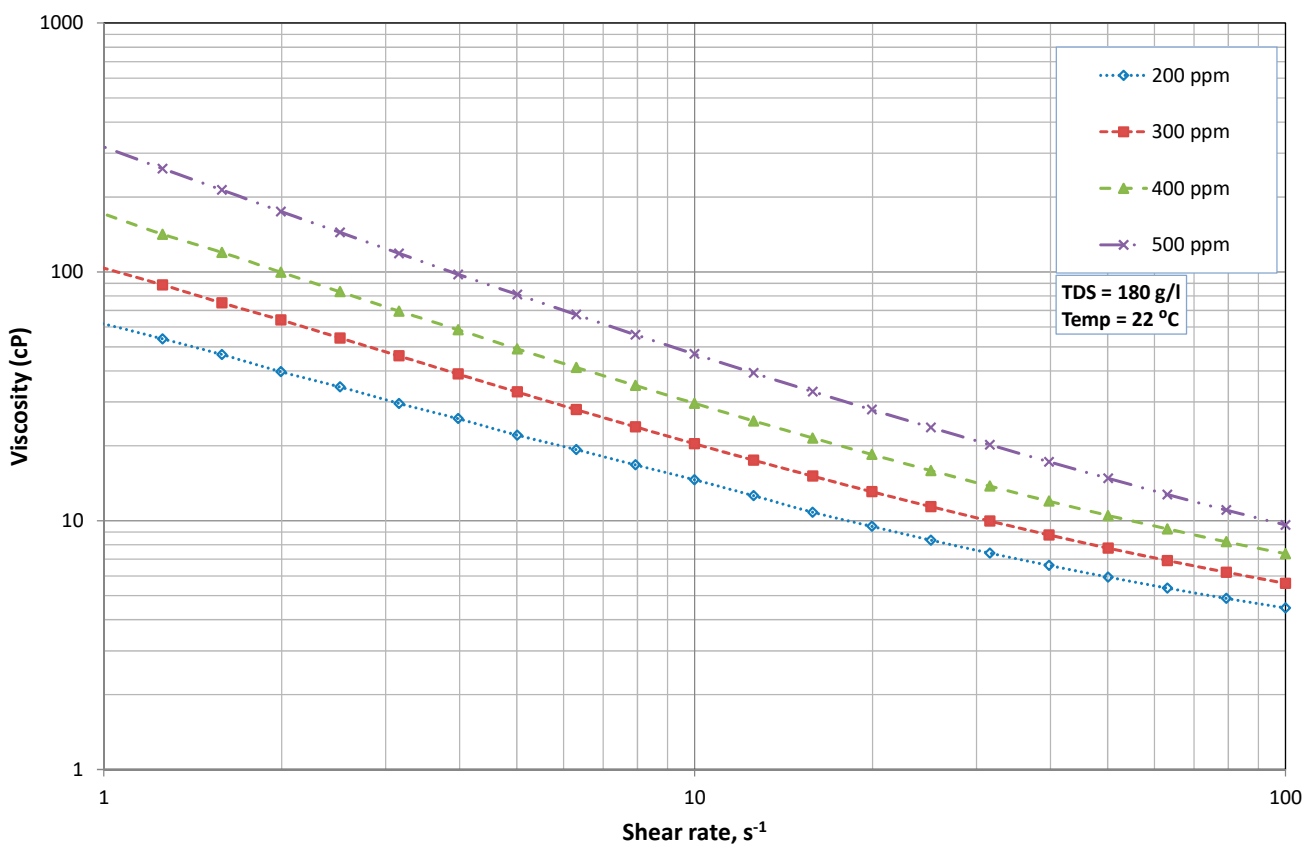

Figure 1. Effect of varying the molar concentration of the screening samples on the biopolymer solution viscosity.

\subsection{Characterization and Evaluation}

Rheological analysis was performed for all biopolymer solution screening samples and the targeted samples. The target sample viscosity was optimized for SAMA brine, whereas the extreme synthetic salinity sample was prepared to explore the salinity effect on the biopolymer solution viscosity. Both samples were then evaluated and further tested to study the thermal stability and mechanical degradation.

\section{Results, Discussion and Evaluation}

\subsection{Polymer Molar Concentration Optimization}

Polymer fluid flow can be expressed by the power-law non-Newtonian in viscosity, $\mu=k \dot{\gamma}^{n-1}$, where $\dot{\gamma}$ is the shear rate and $k$ and $n$ are arbitrary parameters. This equation was the fundamental equation for the optimization routine, which led to estimate the biopolymer solution molar concentration needed to produce the targeted viscosity for the selected reservoir.

The biopolymer solution molar concentration was estimated after fitting the experimental screening data using an IBM SPSS Statistics software package to estimate the required biopolymer solution molar concentration. As a result, the optimal sample was prepared according to the estimated value. The $350 \mathrm{ppm}$ biopolymer solution sample was then prepared with a viscosity of $35 \mathrm{cP}$ at $7.0 \mathrm{~s}^{-1}$. This prepared sample meets the viscosity requirement for polymer flooding in the SAMA oil field reservoir. Figure 2 presents the effect of varying the molar concentration on the biopolymer solution viscosity at a given shear rate for the screening experiments and the optimal sample (SAMA) for the selected reservoir. It is clear that the estimated target sample is bounded between the upper and lower boundaries, which were defined earlier in Table 2. 


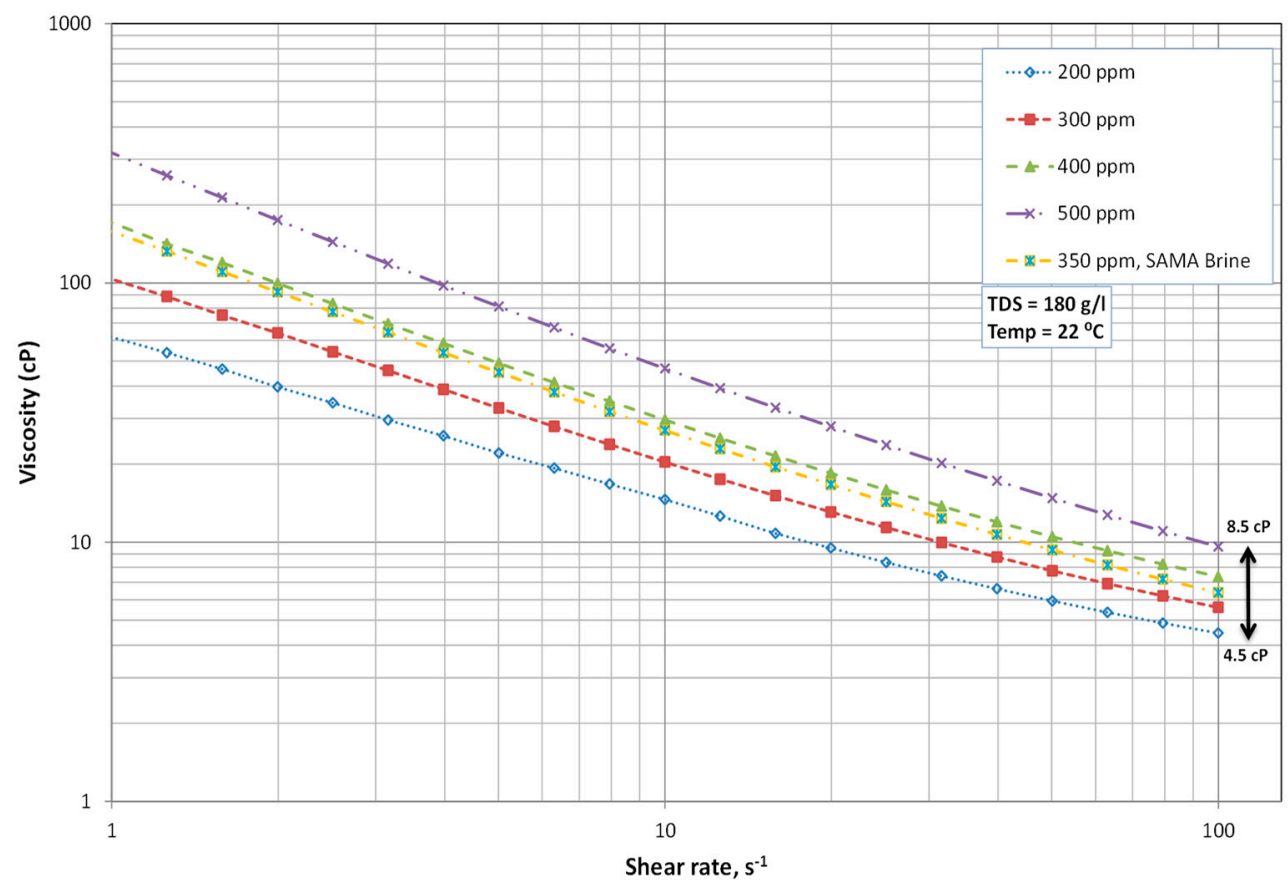

Figure 2. Effect of varying the molar concentration on the biopolymer solution viscosity for the screening experiments and the target sample: The Sabriya-Maudud (SAMA) reservoir.

\subsection{Salinity Effect}

A total of two $350 \mathrm{ppm}$ biopolymer solution samples were analyzed using the HR-3. The first sample was prepared using the $180 \mathrm{~g} / \mathrm{L}$ brine and the second was prepared with the $309 \mathrm{~g} / \mathrm{L}$ brine. This analysis was done to look at the effects of brine salts on the biopolymer solution viscosity.

Figure 3 shows the salinity effect on the biopolymer solution viscosity. As shown in Figure 3, it is observed that, as water salinity increases, viscosity of biopolymer solution increases. This trend shows a direct proportional relation between water salinity and the measured viscosity of the biopolymer solution sample. This is due to the increased amounts of the dissolved solids in the brine and the presence of a higher Sodium Chloride content, which increases the ionic strength of the solution. A similar observation has been reported by Kwak et al. [23]. 


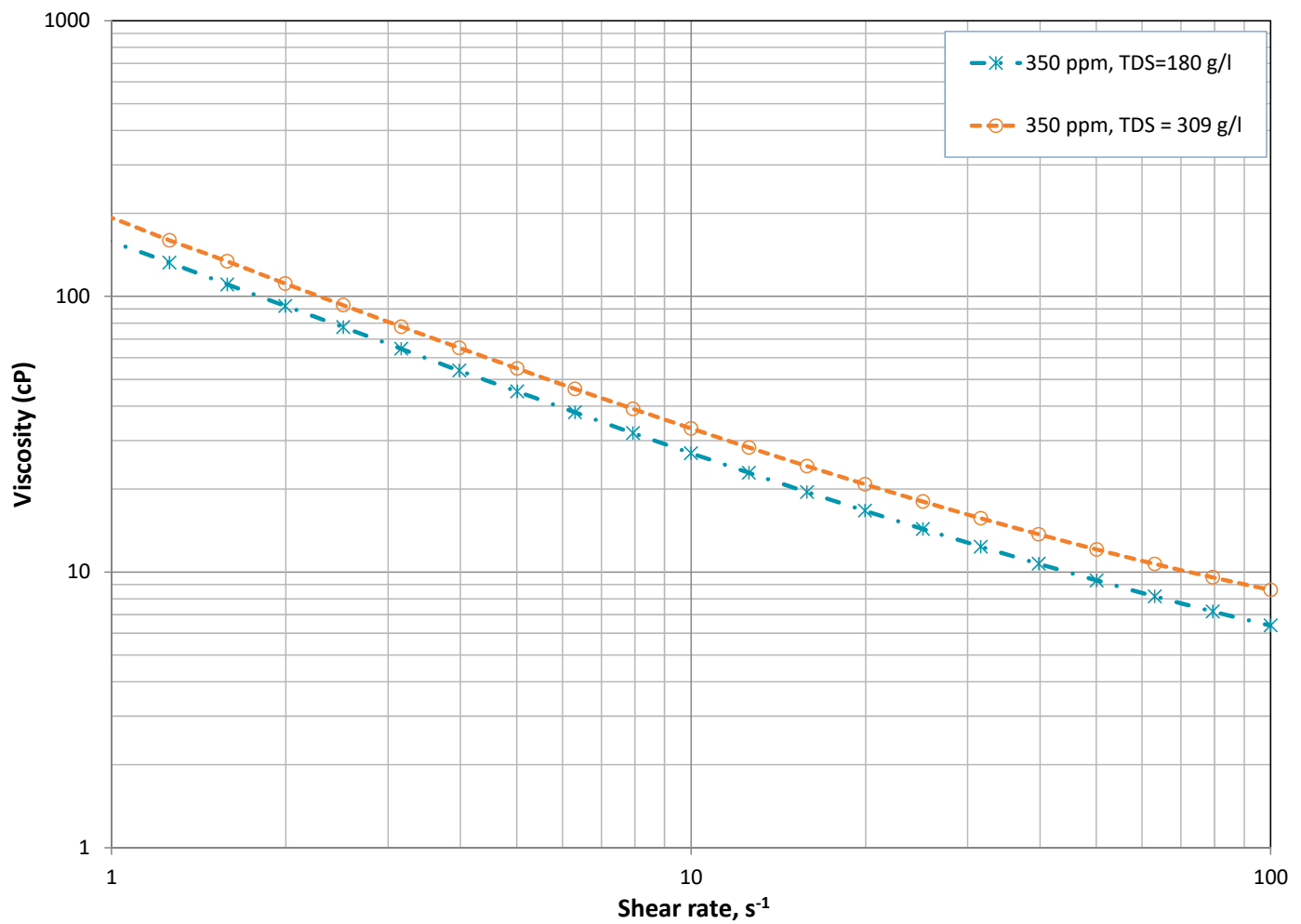

Figure 3. Salinity effect on the measured biopolymer solution viscosity. Total dissolved solids (TDS).

\subsection{Thermal Stability}

The sample preparation for thermal stability experiments was conducted under anaerobic conditions and samples were conditioned and purged with nitrogen at the required temperature for the selected reservoir and extreme temperature. This was followed by rheological and molecular weight characterization.

Thermal stability was an essential step in this research experiments. Two samples were prepared, one using the $180 \mathrm{~g} / \mathrm{L}$ brine and the second using the $309 \mathrm{~g} / \mathrm{L}$ brine. The samples were conditioned and purged with nitrogen in a glass tube with screw caps and placed in a metal cylinder for extreme conditions. This was done in order to simulate the reservoir thermal condition.

The first sample, which was prepared with the $180 \mathrm{~g} / \mathrm{L}$ brine, was kept in an oven at $85^{\circ} \mathrm{C}$ for 11 days, and a sample was taken on the fifth day of the experiment. The second sample, which was prepared with the $309 \mathrm{~g} / \mathrm{L}$ brine, was kept in an oven at $120^{\circ} \mathrm{C}$ for five days to explore the effect of increasing the temperature. In this research, the desired temperature for the SAMA reservoir was $80^{\circ} \mathrm{C}$.

Figure 4 clearly illustrates the biopolymer solution's capability to maintain its properties after the exposure to the $85{ }^{\circ} \mathrm{C}$ heat for 11 days. The biopolymer solution passes the reservoir conditions, with respect to the thermal stability. However, elevating the temperature and salinity to extreme conditions at $120^{\circ} \mathrm{C}$ with $309 \mathrm{~g} / \mathrm{L}$ brine resulted in the deformation of the biopolymer and a sharp decrease in its viscosity, as shown in Figure 5. 


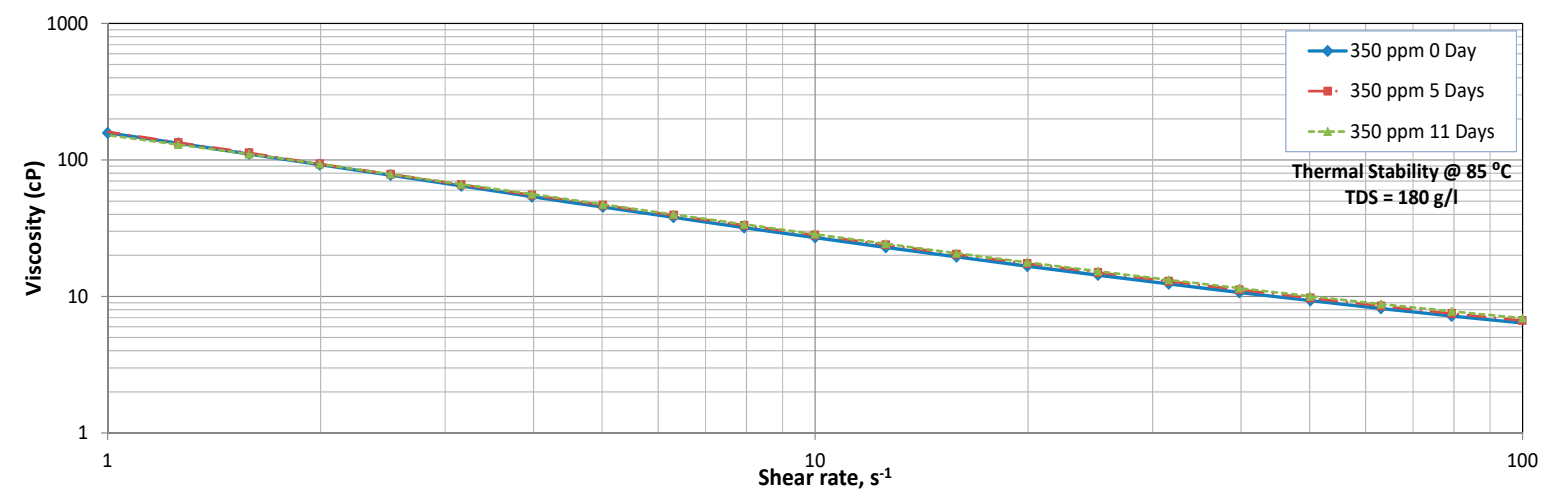

Figure 4. Effect of thermal exposure on biopolymer solution viscosity (SAMA). Brine TDS = $180 \mathrm{~g} / \mathrm{L}$.

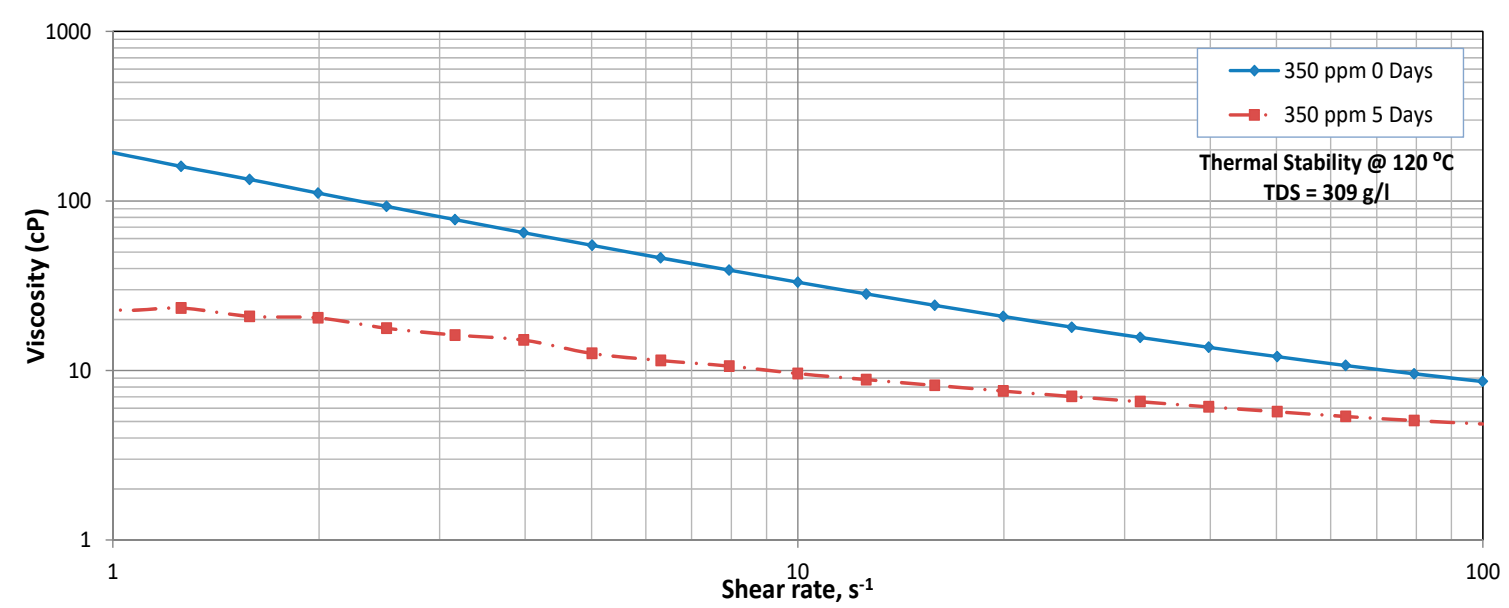

Figure 5. Effect of thermal exposure on biopolymer solution viscosity (extreme conditions). Brine TDS $=309 \mathrm{~g} / \mathrm{L}$.

\section{Temperature Sweep}

The temperature was increased gradually during a small amplitude oscillatory shear to measure the temperature dependence of molecular mobility in the biopolymer solution samples. The temperature was increased from $30{ }^{\circ} \mathrm{C}$ to around $85^{\circ} \mathrm{C}$. The temperature sweep rate was set at $2.5^{\circ} \mathrm{C} / \mathrm{min}$. Figure 6 shows that both samples illustrated acceptable resistance to maintain their targeted properties within this temperature range. 


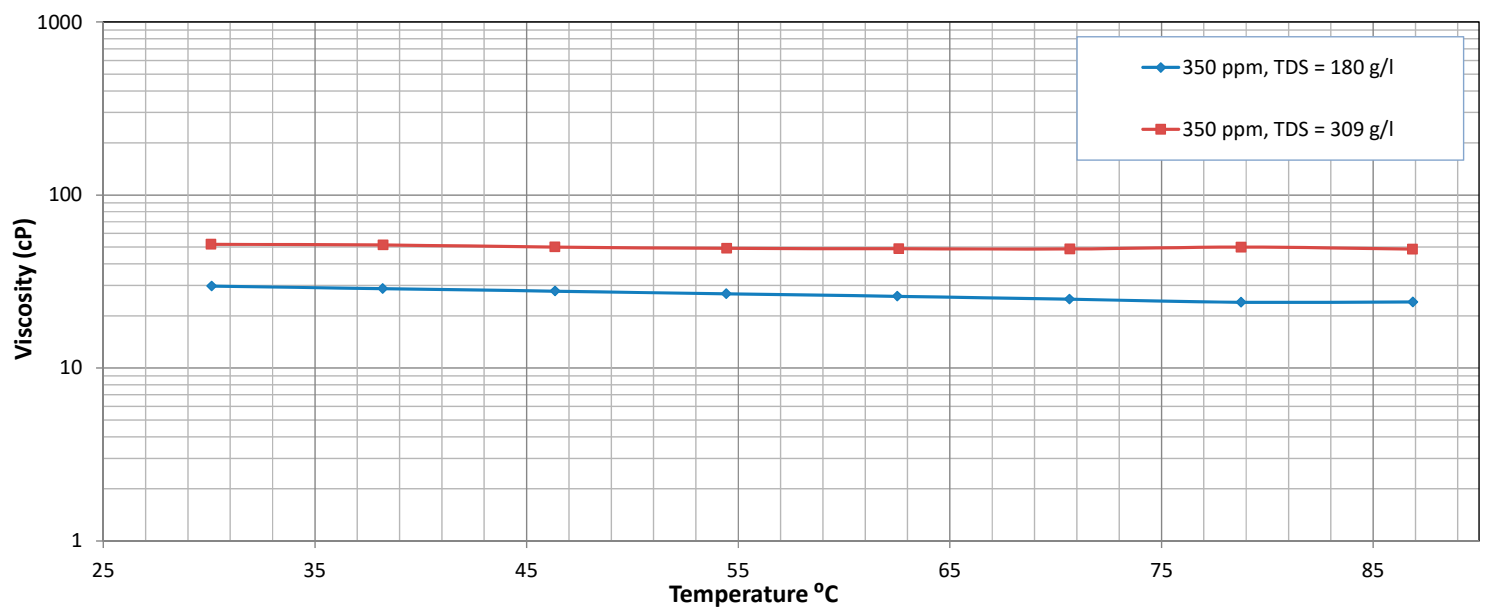

Figure 6. Temperature sweep for the biopolymer solutions using $180 \mathrm{~g} / \mathrm{L}$ and $309 \mathrm{~g} / \mathrm{L}$ brine. TDS: total dissolved solids.

\subsection{Mechanical Degradation}

Two biopolymer solution samples of $25 \mathrm{~mL}$ were transferred to glass tubes to evaluate the biopolymer capability to resist mechanical degradation in the reservoir. The IKA ${ }^{\circledR} \mathrm{T} 10$ basic/ULTRA-TURRAX ${ }^{\circledR}$, Staufen, Germany, a high speed agitator, was used to apply the mechanical shearing to the biopolymer solution samples at 30,000 rpm for $10 \mathrm{~min}$. After shearing, the samples were allowed to settle for $12 \mathrm{~h}$ before testing the degradation effect on the rheological properties. Figures 7 and 8 show the results for the 350 ppm biopolymer solution sample prepared with $180 \mathrm{~g} / \mathrm{L}$ and $309 \mathrm{~g} / \mathrm{L}$ brine, respectively. The results show insignificant change in the biopolymer solution viscosity and reflects acceptable degradation in the biopolymer solution, especially at the shear rate of $7.0 \mathrm{~s}^{-1}$.

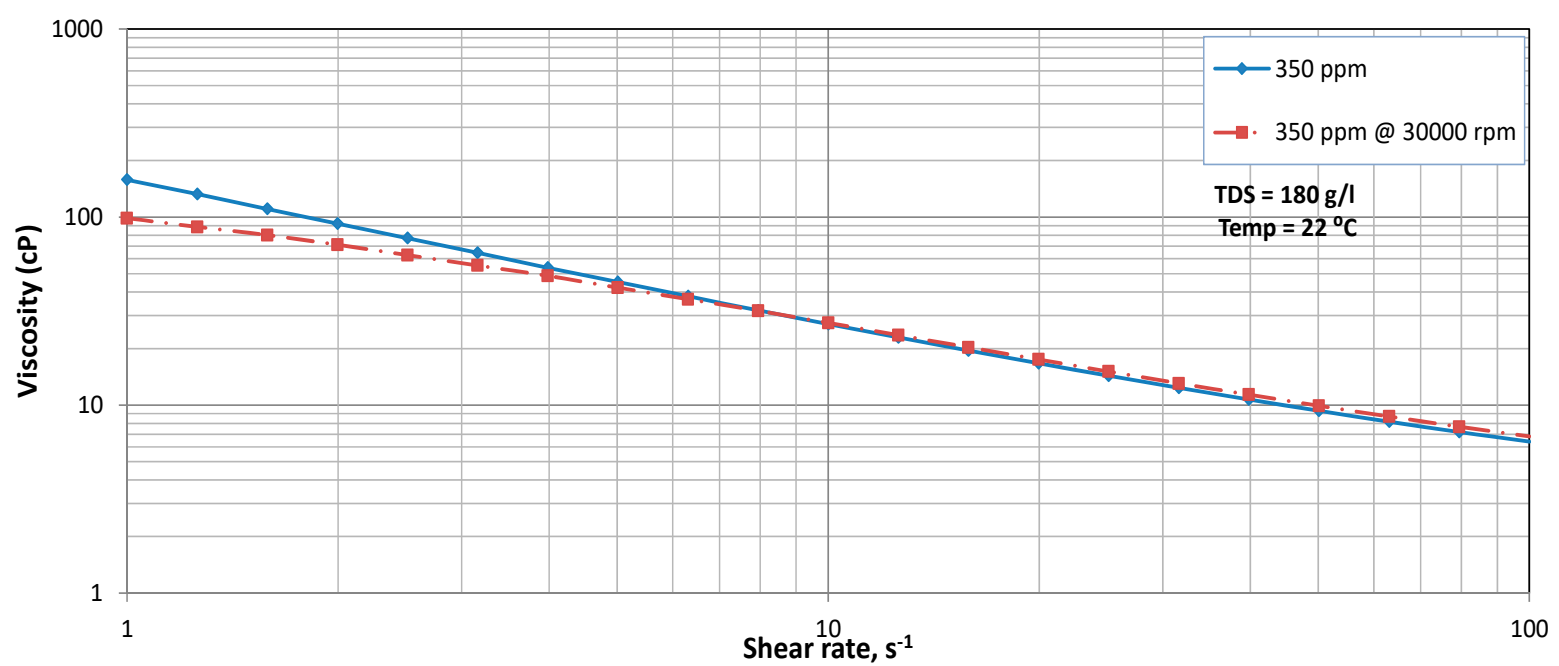

Figure 7. Effect of shearing on biopolymer solution viscosity (SAMA). Brine TDS $=180 \mathrm{~g} / \mathrm{L}$. 


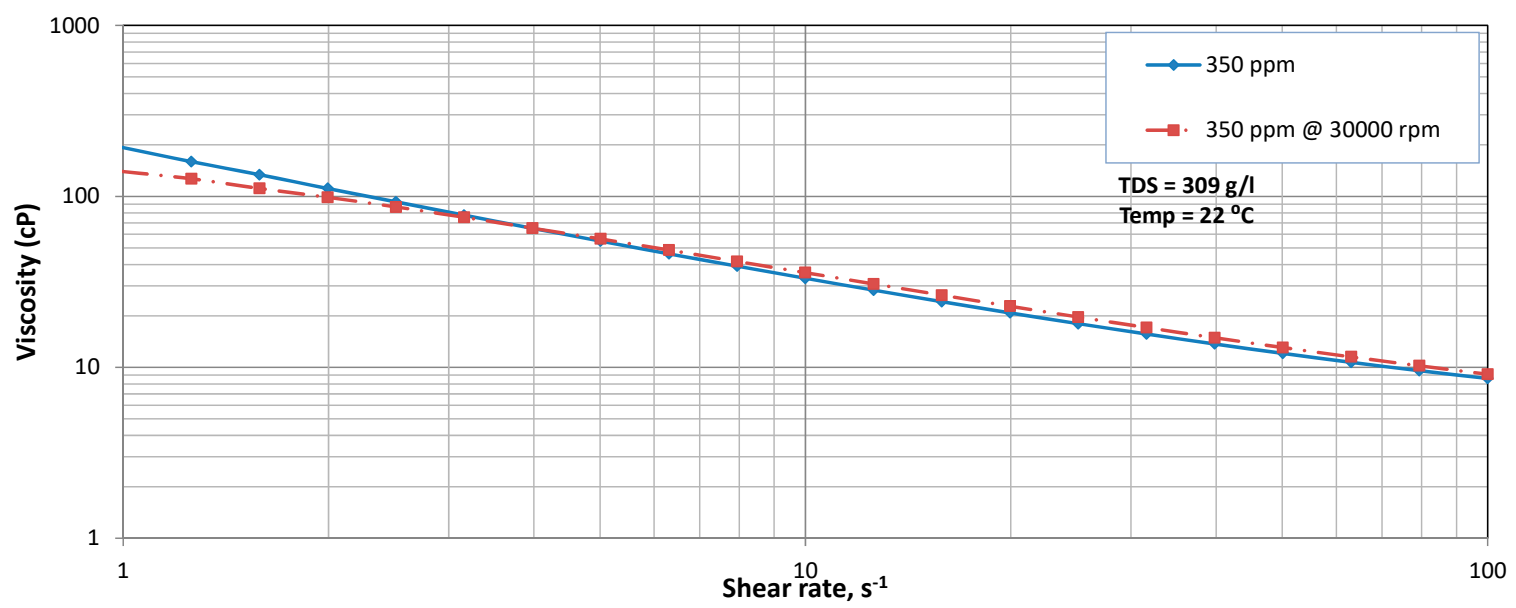

Figure 8. Effect of shearing on biopolymer solution viscosity (extreme conditions). Brine TDS = 309 g/L.

\subsection{Thermal and Mechanical Shear Impact on the Molecular Weight Distribution}

A High Temperature Gel Permeation Chromatography (HT-GPC, Agilent Technologies ${ }^{\circledR}$, Santa Clara, CA, USA), was used to measure the molecular weight distribution of the biopolymer solutions. This analysis was applied after completing the two case studies of the thermal exposure and mechanical shearing for the biopolymer solution samples; those results were compared with the original control sample.

Figure 9 shows the molecular weight distribution of the biopolymer solutions made with the $180 \mathrm{~g} / \mathrm{L}$ brine. The results present a clear deformation in the molecular weight distributions and this degradation, and a breakdown in chain length was noticed while comparing day 11 with day five after the thermal stability tests or after the mechanical shearing. However, the viscosity of the material was not influenced by breaking down the longer chains of the biopolymer samples, as reported in the previous sections.



Figure 9. Molecular weight distribution of the biopolymer solutions made with the $180 \mathrm{~g} / \mathrm{L}$ brine (SAMA). 
Figure 10 shows the molecular weight distribution of the biopolymer solutions made with the $309 \mathrm{~g} / \mathrm{L}$ brine. Similarly, the results present clear deformation in the molecular weight distributions after the thermal stability tests and mechanical degradation analysis.

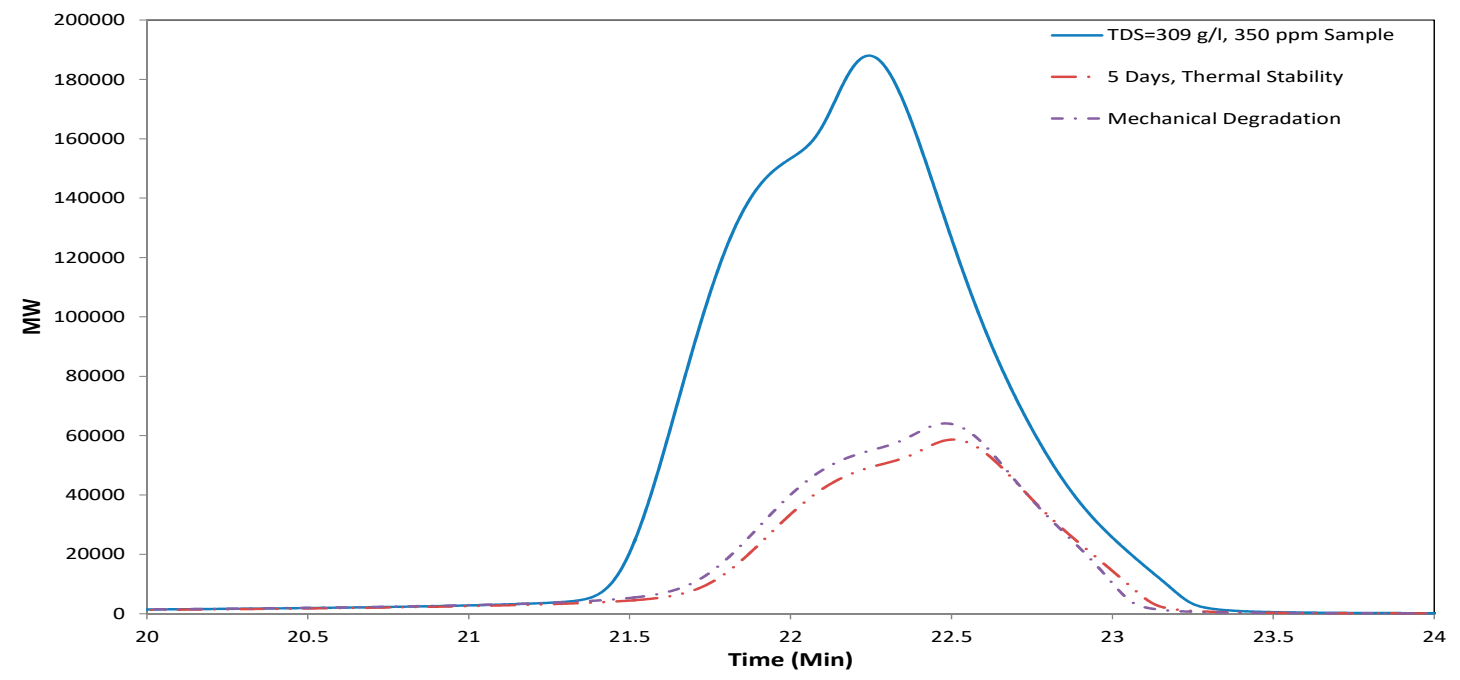

Figure 10. Molecular weight distribution of the biopolymer solutions made with the $309 \mathrm{~g} / \mathrm{L}$ brine (extreme conditions).

\section{Conclusions}

This research provided a comprehensive polymer solution preparation and evaluation methodology for the use in enhanced oily recovery. The developed methodology estimated the molar concentration needed to prepare the biopolymer solution at the targeted viscosity value for the selected reservoir. It also established a systematic evaluation process and demonstrated by example the capability of a potential biopolymer solution for the use in enhanced oil recovery.

The targeted biopolymer solution was prepared with an optimal viscosity of $35 \mathrm{cP}$ at $22{ }^{\circ} \mathrm{C}$ and $7.0 \mathrm{~s}^{-1}$, which meets the requirements for an enhanced oil recovery of the SAMA reservoir in Kuwait. The biopolymer solution sample performance was shown to be acceptable for the use in the enhanced oil recovery polymer flooding, using $180 \mathrm{~g} / \mathrm{L}$ of SAMA brine. It was found that this sample maintained its essential properties while exposed to thermal stability tests and a mechanical degradation analysis. Therefore, it can be introduced as a strong candidate for the use in enhanced oil recovery for the targeted reservoir.

The thermal stability analysis results, for the extreme conditioned sample, show a salinity of $309 \mathrm{~g} / \mathrm{L}$ degraded at the elevated temperature of $120^{\circ} \mathrm{C}$. For mechanical degradation it showed no significant change and maintained its properties. The polymer flooding research is under development and has great potential for a larger impact on enhancing oil recovery to meet international market demands. Therefore, deeper understanding of the relevant environmentally-friendly biopolymer solution behavior, degradation, and interactions is of primary importance to develop novel biopolymer solutions.

Author Contributions: Conceptualization, M.A.A.-S. and M.A.J.; Methodology, M.A.A.-S.; Software, M.A.A.-S.; Validation, A.A.Y.; Formal Analysis, M.A.A.-S., A.H. and T.A.-S. Investigation, M.A.A.-S.; Resources, M.A.A.-S. and T.A.-S.; Data Curation, A.A.Y. and M.A.A.-S.; Writing-Original Draft Preparation, M.A.A.-S.; Writing-Review \& Editing, M.A.A.-S. and A.A.Y.; Visualization, M.A.A.-S., A.H. and T.A.-S.; Supervision, M.A.A.-S.

Funding: This research received no external funding.

Acknowledgments: This research was funded by Kuwait institute for Scientific Research, PC018K. Extended appreciations to the Petroleum Institute of Abu Dhabi for their support in providing essential materials and utilizing their facilities.

Conflicts of Interest: The authors declare no conflict of interest. 


\section{References}

1. Thomas, S. Enhanced oil recovery-An overview. Oil Gas Sci. Technol. Rev. IFP 2008, 63, 9-19. [CrossRef]

2. Vladimir, A.; Manrique, E. Enhanced oil recovery: An update review. Energies 2010, 3, 1529-1575.

3. Sun, Y.; Saleh, L.; Bai, B. Measurement and impact factors of polymer rheology in porous media. Reology 2012, 8, 187-202.

4. Wang, W.; Liu, Y.; Gu, Y. Application of a novel polymer system in chemical enhanced oil recovery (EOR). Colloid Polymer Sci. 2003, 281, 1046-1054. [CrossRef]

5. DaSilva, I.; Lucas, E.; de Franca, F. Study of conditions for polyacrylamide use in petroleum reservoirs: Physical flow simulation in porous media. Chem. Chem. Technol. 2010, 4, 73-80.

6. Leiting, S.; Zhongbin, Y.; Zhuo, Z.; Changjiang, Z.; Shanshan, Z.; Zhidong, G. Necessity and feasibility of improving the residual resistance factor of polymer flooding in heavy oil reservoirs. Pet. Sci. 2010, 7, $251-256$.

7. Du, Y. Field-scale polymer flooding: Lessons learnt and experiences gained during past 40 years. In Proceedings of the SPE International Petroleum Conference in Mexico, Society of Petroleum Engineers 91787, Puebla Pue, Mexico, 7-9 November 2004.

8. Brouzet, C.; Mittal, N.; Lundell, F.; Söderberg, L.D. Characterizing the orientational and network dynamics of polydisperse nanofibers on the nanoscale. Macromolecules 2019, 52, 2286-2295. [CrossRef]

9. Brouzet, C.; Mittal, N.; Söderberg, L.D.; Lundell, F. Size-dependent orientational dynamics of brownian nanorods. ACS Macro Lett. 2018, 7, 1022-1027. [CrossRef]

10. Del Giudice, F.; Tassieri, M.; Oelschlaeger, C.; Shen, A.Q. When microrheology, bulk rheology, and microfluidics meet: Broadband rheology of hydroxyethyl cellulose water solutions. Macromolecules 2017, 50, 2951-2963. [CrossRef]

11. Haward, S.J.; Sharma, V.; Butts, C.P.; McKinley, G.H.; Rahatekar, S.S. Shear and Extensional Rheology of Cellulose/Ionic Liquid Solutions. Biomacromolecules 2012, 13, 1688-1699. [CrossRef] [PubMed]

12. Zamani, N.; Bondino, I.; Kaufmann, R.; Skauge, A. Computation of polymer in-situ rheology using direct numerical simulation. J. Pet. Sci. Eng. 2017, 159, 92-102. [CrossRef]

13. Saavedra, N.F.; Gaviria, W.; Davitt, J. Laboratory testing of polymer flood candidates: San Francisco Field. In Proceedings of the SPE/DOE Improved Oil Recovery Symposium, San Francisco, CA, USA, 13 April 2002; 75182. Society of Petroleum Engineers: Richardson, TX, USA, 2002.

14. Martin, I.; Lozanski, W.R. Taber South-Canada's first polymer flood. In Proceedings of the SPE California Regional Meeting, Santa Barbara, CA, USA, 28-30 October 1970; 3180. Society of Petroleum Engineers: Richardson, TX, USA.

15. Ustick, R.E.; Hillhouse, J.D. Comparison of polymer flooding and waterflooding. In Proceedings of the Society of Petroleum Engineers, Huntington Beach, CA, USA, 19 February 1967; 1734. Society of Petroleum Engineers: Richardson, TX, USA, 1967.

16. Luo, X.; Zhao, C. Practices and experiences of seven-year polymer flooding history matching in China offshore oil field: A case study. In Proceedings of the SPE Reservoir Characterisation and Simulation Conference and Exhibition, Abu Dhabi, UAE, 9-11 October 2011; 147807. Society of Petroleum Engineers: Richardson, TX, USA, 2011.

17. Dong, H.Z. Review of practical experience and management by polymer flooding at Daqing. In Proceedings of the SPE Symposium on Improved Oil Recovery, Tulsa, OK, USA, 20-23 April 2008; 114342. Society of Petroleum Engineers: Richardson, TX, USA, 2008.

18. He, L. An enhanced oil recovery technology continually after polymer-flooding. In Proceedings of the SPE Enhanced Oil Recovery Conference, Kuala Lumpur, Malaysia, 19-21 July 2011; 144250. Society of Petroleum Engineers: Richardson, TX, USA, 2011.

19. Tabary, R.; Bazin, B. Advances in chemical flooding, improved oil recovery (IOR) techniques and their role in boosting the recovery factor. In Proceedings of the IFP-OAPEC Joint Seminar, Rueil-Malmaison, France, 26-28 June 2007.

20. Gao, C. Application of a novel biopolymer to enhance oil recovery. J. Petrol. Explor. Prod. Technol. 2016, 6, 749-753. [CrossRef]

21. Zhang, Y.; Kong, H.; Fang, Y.; Nishinari, K.; Phillips, G.O. Schizophyllan: A review on its structure, properties, bioactivities and recent developments. Bioactive Carbohydr. Diet. Fibre 2013, 1, 53-71. [CrossRef] 
22. Al-Matrouk, M.F.; Oskui, R.P.; Al-Qahtani, M.M. Assessment of Enhanced Oil Recovery (EOR) Techniques for Selected Fifteen Kuwait Reservoirs; Report No. KISR9550; Kuwait Institute for Scientific Research: Kuwait, Kuwait, 2009.

23. Kwak, H.-T.; Zhang, G.; Chen, S. The effects of salt type and salinity on formation water viscosity and NMR responses. In Proceedings of the International Symposium of the Society of Core Analysts, Toronto, ON, Canada, 21-25 August 2005. 